\title{
Nanoparticle Paclitaxel (Nanoxel) as a Safe and Cost-Effective Radio-Sensitizer in Locally Advanced Head and Neck Carcinoma
}

\author{
Akshay Nigam ${ }^{1}$, Anupama Sharma ${ }^{2}$, Sanjeev Kumar Singh ${ }^{2}$ \\ ${ }^{1}$ Department of Radiation Oncology, G. R. Medical College, Gwalior, India; ${ }^{2}$ Department of Biochemistry, G. R. Medical College, \\ Gwalior, India. \\ Email: shanuanupama@gmail.com
}

Received November $8^{\text {th }}, 2011$; revised December $23^{\text {rd }}, 2011$; accepted January $8^{\text {th }}, 2012$

\begin{abstract}
Squamous cell carcinoma of the head and neck (SCCHN) is a common malignancy. It is the $7^{\text {th }}$ most common malignancy. Approximately 45,000 new cases are diagnosed each year in the USA. In present study 10 patients were selected of age group between 40 - 60 years from Gwalior-Chambal region, among them 3 were females and 7 were males. 3 patients were suffering from tonsilitis, 4 from Laryngeal carcinoma, 2 from carcinoma in maxillary antrum and 1 patient was suffering from carcinoma of whole tongue. The aim of present study is to evaluate the safety of nanoparticle paclitaxel (Nanoxel, a plant alkaloid) in combination with radiation in the treatment of locally advanced head and neck carcinoma. Further the patients were divided in 2 groups. The $1^{\text {st }}$ group received nanoxel (plant alkaloid) administered concomitantly with radiation therapy. $2^{\text {nd }}$ group received gemcitabine administered in combination with radiation therapy. 9 patients showed response for the therapy. The adverse effects in arm A, 2 patients showed anemia less than $8 \mathrm{gm}$ of Hemoglobin, 2 patient showed leucopenia and 1 patient showed diarrhoea, Nausea/vomiting were shown by 4 patients, in arm B, 1 patient showed leucopenia, 1 patient showed anemia less than 9 gm hemoglobin and 5 patient showed sensory neuropathy. Nanoxel (plant alkaloid) showed best results in the case of head and neck carcinoma. The dose of $30 \mathrm{mg} / \mathrm{kg}$ b.w showed best safety with best clinical effect in term of less time of patient admission (hardly $30 \mathrm{mins}$ ) with less side effects with greater clinical effects in our study.
\end{abstract}

Keywords: Nanoxel; Plant Alkaloid; Paclitaxel; Carcinoma; Radiation; Chemotherapy

\section{Introduction}

SCC or SqCC is occasionally rendered as "squamous-cell carcinoma”, histological its distinct form carcinoma. It arises from the uncontrolled multiplication of malignant cells derive from epithelium, or showing particular cytological or tissue architectural characteristics of squamous cell differentiation, such as the presence of keratin, tonofilament, bundles and desmosomes. Squamous cell carcinoma is one of the most common carcinomas in humans and other animals. $90 \%$ of head and neck carcinoma is SQCC [1], originating from the mucosal lining (epithelium) of these regions [2]. It usually arises from mutated ectodermal or endodermal cells lining of the body cavities. Therefore, it can develop in a large number of organs and tissues, including the skin, lips, mouth, esophagus, urinary bladder, prostate, lung, vagina, and cervix. Most cervical cancers are squamous cell carcinomas, arising in the squamous (flattened) epithelial cells that line the cervix. Squamous Cell Carcinoma is the most common type of cancer of upper part of vagina, the other types of carcinoma affecting vagina are adeno carcinoma and malignant melanomas sarcoma.

Paclitaxel is a chemotherapeutic agent which acts by stabilizing microtubules, resulting in a block of cell cycles at G2 and M. Since G2 and M are the most radiosensitive phases of cell cycle, paclitaxel is an efficacious cell cycle specific radiosensitizer. It is an anti-carcinoma ("antineoplastic" or "cytotoxic") chemotherapeutic drug, classified as a "plant alkaloid", a "taxane" and an "antimicrotubule agent".

Paclitaxel is a diterpenoid alkaloid drug approved by food and drug administration (FDA) and European medical agency as a first line therapy of breast and ovarian carcinoma, with proven effects against carcinomas of other tissues. Taxol was the first marketed formulation of paclitaxel, introduced into market in 1992 as second line treatment of advanced ovarian carcinoma [3].

The prognosis is dependent upon the stage at presentation. As a group, over $70 \%$ of patients with stage I and stage II SCCHN are curable with standard therapy (radi- 
ation therapy). Unfortunately, most patients present with stage III or IV disease and only about $50 \%$ of patients with these are curable. Chemotherapy and radiation are used simultaneously. The drug and radiation may act against differing subsets of tumor cells. Although radiation enhances the antagonist effect of drug, when provided in combination with chemotherapy, therefore we used very mild dose of $30 \mathrm{mg} / \mathrm{kg}$ b.w of drug, to minimize the antagonist effect of the radiation on chemotherapy. This increased recruitment of cells into radiation responsive phase of cell cycle. Chemotherapy inhibits repair of sub-lethal radiation damage. The nanoxel have poor solubility, cremophor, polyethoxylated castor oil show hypersensitivity reactions.

Nanoparticles themselves can also be used to destroy carcinoma cells directly. Metallic nanoparticles, together with near infrared light, have been shown to increase cell death in tumors by generating hyperthermia [4,5]. Gold nanoparticles inhibit angiogenesis by binding to vascular endothelial growth factor and basic fibroblast growth factor and preventing them from activating their receptors [6].

In the present study we introduced new plant nanoparticle paclitaxel which is being used as a good chemotherapeutic. Very low dose of paclitaxel $30 \mathrm{mg} / \mathrm{kg}$ b.w is provided to the patients to evaluate the efficiency of paclitaxel in carcinoma cases.

\section{Material and Methods}

Total number of patients selected in the study were 10 , of age group between 40 to 60 years. There were 3 females and 7 males. Loco was regionally advanced, biopsy was done and proven squamous cell carcinoma with stage 2B 3B of head and neck of the carcinoma patients. 3 patients were having tonsil, 4 with Laryngeal carcinoma, 2 with carcinoma in maxillary antrum and 1 patient had carcinoma of whole tongue Table 1.

All the eligible patients were divided in 2 groups. Group 1 received the therapy of nanoxel administered concomitantly with radiation therapy. Group 2 received gemcitabine administered in combination with radiation therapy.

All eligible patients of group 1 received nanoxel (plant alkaloid) $30 \mathrm{mg}$ administered i.v. (intra venous) over 1 hour weekly starting from $2^{\text {nd }}$ to $7^{\text {th }}$ week (total 6 weeks); given two hours prior to radiation therapy.

Table 1. Number of patients and cancer type with staging and responses.

\begin{tabular}{cccc}
\hline Cancer type & $\begin{array}{c}\text { No of } \\
\text { patients }\end{array}$ & Staging & $\begin{array}{c}\text { Response after } \\
\text { radiotherapy }\end{array}$ \\
\hline Laryngeal & 4 & IInd and IIIrd B & $90 \%$ response \\
Base of Tongue & 3 & IInd and IIIrd B & $90 \%$ response \\
Tonsils & 3 & IInd and IIIrd B & $90 \%$ response \\
\hline
\end{tabular}

Radiation therapy was administered in a fraction of 200 cGy per day x 5 - 6 days of the week (total dosage 70 Gy) with a reducing field technique continued for 6 weeks.

Patients of group B received gemcitabine were administered intravenously over 30 min once weekly, 1 - 2 hrs before radiation, for 7 consecutive weeks at $100 \mathrm{mg} / \mathrm{m}^{2}$ or $50 \mathrm{mg} / \mathrm{m}^{2}$. Radiotherapy was delivered once daily, 5 days a week as a single $2 \mathrm{~Gy}$ fraction. The total dose was $70 \mathrm{~Gy}$, intended to be delivered over 7 weeks. Patients of group 3 received radiation alone.

\section{Result}

On the basis of local evaluation $90 \%$ of patients were identified as responders. Side effects were identified as in $10 \%$ of patients. The adverse effects in arm A, 2 patients showed anemia less then $8 \mathrm{gm}$ of $\mathrm{Hb} 2$ patient showed leucopenia and 1 patient showed diarrhoea, nausea/vomiting were shown by 4 patients, in arm B 1 patient showed leucopenia and 1 patient showed anemia less then $9 \mathrm{gm}$ $\mathrm{Hb}$ and 5 patients showed sensory neuropathy.

All the above side effects were evaluated on the basis of weekly complete blood count, liver function test and renal function test before providing chemotherapy. Every patient was weekly evaluated for local side effect and any sign of side effect.

\section{Discussion}

Many new discovered anticarcinoma drugs are derived from natural products and biological substances. Although novel technologies are applied in health care and medical process, anticarcinoma drug discovery is still in need, since the highly effective drug with less toxicity is one of the crucial fields for the treatment of carcinoma. Alkaloids derived from plant products are used since last 20 yrs in various carcinoma diseases, especially in breast and head carcinoma. Most common drug is taxol. In traditional taxol, cramophore is used as a solvent which makes the particles bigger, so that absorption of the drug is very low and hypersensitivity reactions are very poor. The first drug made by nanotechnology in the field of oncology is nanoxel (plant alkaloid), in which traditional taxol is fragmented into micro-molecules, so that drug absorption is very easy and there is no need of chromophore as a solvent [7]. Nanoxel can be used in higher amount, because the effectiveness of drug is very high. Nanoparticles themselves are used to destroy carcinoma cells directly. With infrared light they increase cell death in tumors by generating hyperthermia [2]. Paclitaxel a chemotherapeutic agent stabilizing microtubules resulting in a block of cell cycles at G2 and M. Since G2 and $\mathrm{M}$ are the most radiosensitive phases of cell cycle use of paclitaxel is done on this specific phases to check cancer [8]. 


\section{Conclusion}

Nanoparticle paclitaxel (Nanoxel) (plant alkaloid) are very effective and safe radio-sensitizer in locally advanced Head and Neck Carcinoma, it's an efficacious cell cycle specific, radio sensitizer. It is a very cost effective option especially in doses that we have tried: $30 \mathrm{mg} / \mathrm{kg}$ b.w weekly. 9 patients were identified as responders for the therapy. Side effects were identified as in 2 patients. Responses of the patients are being concluded on the basis of two groups only.

\section{REFERENCES}

[1] J. A. Ridge, B. S. Glisson, M. N. Lango, et al., "Head and Neck Tumors,” In: R. Pazdur, L. D. Wagman, K. A. Camphausen and W. J. Hoskins, Eds., Cancer Management: A Multidisciplinary Approach, 11th Edition, CMP, London, 2008.

[2] http://www.macmillan.org.uk/Cancerinformation/Cancert ypes/Headneck/Aboutheadneckcancers/Typesofheadneck cancer.aspx

[3] S. Doctorova, C. Martin and S. Eliana, "Lipid Nanoparti- cle Mediated Drug Delivery for Safer Carcinoma Treatment: Example of Paclitaxel,” Revista da Faculdade de Ciencias da Saude, Vol. 6, 2009, pp. 84-93.

[4] L. R. Hirsch, R. J. Stafford, J. A. Bankson, et al., "Nanoshell-Mediated near Infrared Thermal Therapy of Tumor under Magnetic Resonance Guidance,” Proceeding of National of Science of the United States of America, Vol. 100, No. 23, 2003, pp. 13549-13554. doi:/10.1073/pnas.2232479100

[5] W. C. Hahn and R. A. Weinberg, "Modeling of Molecular Circuitry of Carcinoma," Nature Reviews Cancer, Vol. 2, No. 5, 2002, pp. 331-341. doi:/10.1038/nrc795

[6] L. Liotta and E. Petricoin, "Molecular Profiling of Human Carcinoma,” Nature Reviews Genetics, Vol. 1, 2000, pp. 48-56. doi:/10.1038/35049567

[7] P. Alivisatos, "Use of Nanocrystals in Biological Detection,” Nature Biotechnology, Vol. 22, No. 1, 2004, pp. 47-52. doi:/10.1038/nbt927

[8] A. P. Alivisatos and W. W. Gu, "Quantum Dots as Cellular Probes,” Annual Reviews of Biomedical Engineering, Vol. 7, No. 1, 2005, pp. 55-76. doi:/10.1146/annurev.bioeng.7.060804.100432 